\title{
Capital Social em Brasília na Perspectiva de Nativos e Emigrantes
}

Social Capital In Brasilia In The Perspective Of Natives And Immigrants

Capital Social En Brasilia En La Perspectiva De Nativos E Inmigrantes

\author{
Gemael Chaebo \\ Professor Doutor, UFMS, Brasil. \\ gemaelchaebo@gmail.com \\ Natália Fernandes Silveira \\ Mestranda, UFMS, Brasil. \\ nataliafernandessilveira@gmail.com \\ Vítor Cardoso da Silveira \\ Professor Mestre, UFMS, Brasil. \\ cardosovitorsilveira@gmail.com
}


RESUMO

Este artigo pretende identificar e comparar o capital social em Brasília na perspectiva de nativos e emigrantes. 0 marco teórico baseou-se no constructo sobre capital social, tentando identificar fatores que poderiam demonstrar sua presença ou ausência no contexto brasiliense. Com relação aos métodos, a pesquisa englobou apenas questões relacionadas a confiança para que se pudesse ter condições de inferir sobre o capital social nos diferentes grupos. A pesquisa foi qualitativa e descritiva, na qual a estratégia de investigação utilizada foi o estudo multicasos, que permite a comparação entre grupos de participantes. $O$ instrumento de coleta utilizado foi um roteiro contendo apenas questões abertas aplicado a oito estudantes de Pós-Graduação, sendo quatro deles nativos e quatro emigrantes à cidade. Os dados foram analisados por meio de análise de conteúdo. Os principais resultados indicam que os emigrantes sensivelmente confiam mais em seus pares, nas autoridades públicas e nas instituições do que os participantes nativos. A pesquisa contribui para (a) entender as percepções referentes a confiança entre nativos do Distrito Federal e emigrantes; assim como, este estudo permite (b) inferir sobre o capital social existente em cidades "construídas" artificialmente.

PALAVRAS-CHAVE: Capital Social. Confiança. Estudo multicasos.

\section{ABSTRACT}

This article intends to identify and compare the social capital in Brasilia from the perspective of natives and emigrants. The theoretical framework was based on the construct about social capital, trying to identify factors that could demonstrate its presence or absence in the Brazilian context. Regarding methods, the research encompassed only questions related to trust so that one could be able to infer about social capital in different groups. The research was qualitative and descriptive, in which the research strategy used was the multicasos study, which allows the comparison between groups of participants. The collection instrument used was a script containing only open questions applied to eight Postgraduate students, four of them native and four emigrants to the city. Data were analyzed through content analysis. The main results indicate that migrants significantly rely more on their peers, public authorities and institutions than the native participants. The research contributes to (a) understanding the perceptions regarding trust between natives of the Federal District and emigrants; as well as, this study allows (b) to infer about the social capital existing in artificially "built" cities.

KEYWORDS: Social Capital. Confidence. Multi-purpose study.

\section{RESUMEN}

Este artículo pretende identificar y comparar el capital social en Brasilia en la perspectiva de nativos y emigrantes. El marco teórico se basó en el constructo sobre capital social, intentando identificar factores que podrían demostrar su presencia o ausencia en el contexto brasiliense. Con respecto a los métodos, la investigación englobó sólo cuestiones relacionadas con la confianza para que se pudiera tener condiciones de inferir sobre el capital social en los diferentes grupos. La investigación fue cualitativa y descriptiva, en la cual la estrategia de investigación utilizada fue el estudio multicas, que permite la comparación entre grupos de participantes. El instrumento de recolección utilizado fue un guión que contenía sólo preguntas abiertas aplicado a ocho estudiantes de Postgrado, siendo cuatro de ellos nativos y cuatro emigrantes a la ciudad. Los datos fueron analizados por medio de análisis de contenido. Los principales resultados indican que los emigrantes sensiblemente confían más en sus pares, en las autoridades públicas y en las instituciones que los participantes nativos. La investigación contribuye a entender las percepciones referentes a la confianza entre nativos del Distrito Federal y emigrantes; así como, este estudio permite (b) inferir sobre el capital social existente en ciudades "construidas" artificialmente.

PALABRAS CLAVE: Capital Social. La confianza. Estudio multicasos. 


\section{Introdução}

Capital social é uma forma de capital, no qual engajamento político e confiança mútua são capazes de regular complexas relações sociais, diminuindo assimetrias de informação e oportunismo dos agentes. O capital social surge como instituição informal, orientando ações coletivas quando o arcabouço institucional-legal não se mostra favorável, demonstrando que propostas de engajamento cívico são fundamentais a manutenção e reprodução do bem-social (PUTNAM, 1995; LIN, 1999). Por meio de uma matriz de créditos e obrigações, produz-se artifícios para a reciprocidade e cumprimento de obrigações mútuas, base para a confiança e cooperação (COLEMAN, 1990; PORTES, 1998; HIGGINS, 2005). Para Fukuyama (1996) e Vilpoux e Oliveira (2010), a reciprocidade pode estar presente tanto no entendimento entre dois amigos, quanto na base de sustentação de doutrinas.

Teorias femininas começam a contestar a excessiva racionalidade do viés masculino, ampliando as possibilidades de construção para novas formas organizacionais, e são fundamentadas sobre aspectos convencionais que perpassam pelas experiências individuais e identidades coletivas. Estas teorias muitas vezes deixam a desejar em capitais físicos, financeiros ou que gerem ativos considerados "reais"; mas abrem espaço ao desenvolvimento humano e a formação de capital social (SCOTT, 1998).

Putnam (1996) indica algumas causas da queda do capital social, entre elas: mobilidade transacional, características demográficas diversas (menos casamentos, mais divórcios, menos filhos, etc.) e individualização das formas de lazer. Callahan (1996) afirma ainda que existe uma relação inversamente proporcional entre renda e a quantidade de capital social existente, fator que diminui a dependência em relação aos outros indivíduos. Levando em considerações esses fatores, a presente pesquisa foi realizada em Brasília - capital do Brasil.

Alguns fatores justificam a escolha da capital: Brasília completou recentemente 58 anos, assim sua ocupação é bastante recente (mobilidade transacional); sua renda média per capita é uma das mais altas do país; e detém um dos maiores índices de separações conjugais do país. Assim, surge a seguinte questão de pesquisa: Qual o nível de capital social em Brasília? Para isso, foram convidados a participar da pesquisa estudantes de Pós-Graduação de uma universidade pública de Brasília, os quais metade é nativo à cidade e a outra metade é emigrante de outras regiões do país.

Desta forma, o objetivo geral deste artigo é: Comparar o capital social de Brasília na perspectiva de nativos e emigrantes. Embora o capital social possa ser observado sob diversas perspectivas, adotou-se apenas questões relacionadas à confiança em nativos e emigrantes, de modo que se permita estabelecer comparações entre os grupos. A confiança foi utilizada como um indicador da presença de capital social. A presente pesquisa contribui para a observação de como diferentes grupos interagem em um mesmo contexto, de maneira que suas características particulares sejam destacadas. A comparação entre as características que afetam a confiança nestes dois grupos permite entender os pontos considerados relevantes no estabelecimento de relações coletivas, o que afeta por consequência a maneira como as relações sociais são estruturadas. 


\section{Revisão da Literatura}

É impossível entender o funcionamento do mundo social sem reapresentar o conceito de capital e as facetas que governam seu funcionamento (PORTES, 1998). Sua abordagem econômica reduziu o universo de trocas às transações mercantis, orientadas para a maximização de lucros e auto interesse. Porém, existem outras formas de capitais não-econômicos e desinteressados; isto é, que não produzem contrapartes (BORDIEU, 1985), ou melhor dizendo, que não apresentam retornos decrescentes (MARTELETO; SILVA, 2004).

As facetas de capital apresentadas por Bordieu (1985) são: a) Econômica - aquela imediatamente convertida em moeda e institucionalizada em direitos de propriedade; b) Cultural (humano) pode ser convertida em capital econômico e é institucionalizada na forma de qualificações profissionais; e c) Social - construída sobre obrigações sociais que podem ser convertidas em capital econômico e são institucionalizadas na forma de títulos de "nobreza" (reputação).

Os estoques de cada um destes tipos de capitais são armazenados de forma diferenciada. 0 capital econômico está contido no banco, o cultural presente na cabeça dos indivíduos, mas o capital social é preservado nos relacionamentos (PORTES, 1998). Para Fukuyama (1996), o capital social é resultado de uma construção coletiva e histórica, que depende da cooperação (hábitos, normas e tradições) praticada ao longo do tempo para que seja observada em determinada região, sendo fruto da ação coletiva e não pertencendo ao indivíduo. Scott (1998) considera importantes as três abordagens para as estruturas organizacionais, pois estas são formadas a partir da fusão de capitais financeiros, humanos e sociais. Embora todas as abordagens sejam fundamentais ao entendimento das relações societais, o foco deste artigo debruça-se sobre o conceito de capital social.

O termo capital social foi cunhado pela primeira vez em 1916 por L. H. Hanifam, afirmando que as interações entre as pessoas são o que mais importa em suas vidas; os vínculos de boa vontade ou amizade sem os quais o indivíduo estaria só, sem defesas sociais (PUTNAM, 2000). A princípio observou-se o papel de uma sociedade forte e engajada para a consolidação da democracia.

Aparentemente, fatores como participação eleitoral, assinaturas de jornais e participação em clubes de corais ou esportivos fazem que com melhorem os índices de educação, saúde, emprego, pobreza, crime, etc.; tornando-se marcas de uma região bem sucedida. Desta forma, estes efeitos não são apenas consequência do desenvolvimento, mas pré-requisito para que pudesse ocorrer. A estes engajamentos cívicos foi dado o nome de "capital social" (PUTNAM, 1993, 1995; ALBAGLI; MACIEL, 2002).

Sob essa perspectiva, a visão da luta constante entre classes tem sido deixada de lado, voltando o foco para a comunidade, que por meio de seus agentes compartilha e facilita entre as pessoas o sentimento de identidade comum. Desta forma, o sucesso das instituições comunitárias depende do contexto cívico, cultural e político gerado a partir da confiança e solidariedade (BRANDÃO, 2007). Putnam (1995, p. 6) afirma que "confiança e engajamento são duas facetas de mesmo valor subjacente - o capital social".

A importância do capital social começa a ser observada a partir de uma série de estudos empíricos, que comparou índices de desenvolvimento entre países com capacidades de capital (físico, humano e financeiro) equivalentes, mas que resultaram em níveis diferentes de 
crescimento. Concluiu-se que somente os fatores econômicos já não eram mais capazes de traduzir porque alguns territórios e regiões se desenvolvem mais rapidamente que outras (EVANS, 1996; ALBAGLI; MACIEL, 2002), demonstrando outras fontes de poder e influência provenientes de fatores não-econômicos (PORTES, 1998).

O conceito de capital social surge para auxiliar a compreender como as variáveis extraeconômicas facilitam nesta dinâmica. Para isso, é necessário entender que além do Estado e do mercado, existem formas diferentes de coordenação alicerçadas por organizações e instituições (formais e informais) que compõem um arranjo institucional próprio (MULS, 2008). Segundo Vilpoux e Oliveira (2010), as formas híbridas de coordenação transitam entre os contratos e a confiança. Nesse cenário, a confiança torna-se uma ferramenta para a redução dos custos de transação (COSTA, 2003; MARTELETO; SILVA, 2004).

Outro ponto a ser levantado sobre o capital social são seus direcionamentos teóricos. Para Higgins (2005, p. 29), "a construção do capital social é uma espécie de elipse com dois focos", sendo um político e outro econômico. No político, as assimetrias de informação facilitadas pela relação social auxiliam na obtenção de recursos. No econômico, por outro lado, as simetrias de informação estruturam as relações sociais (HIGGINS, 2005).

Pelo ponto de vista político, Bordieu (1985) foi o primeiro a apresentar o conceito de capital social, ao perceber que os fluxos entre os agentes não se limitavam às trocas comerciais e aos direitos de propriedade. $O$ poder vinculado às estruturas sociais se torna uma forma de capital (HIGGINS, 2005).

O foco econômico repousa sobre as ferramentas que auxiliam os indivíduos a alcançarem seus objetivos (HIGGINS, 2005). Coleman (1990) propõe o uso de capital social para resolução de problemas de ação coletiva com uma abordagem funcional; para ele, o indivíduo racional tem motivos de se enquadrar dentro de uma estrutura coletiva, visando facilitar suas ações. Para Putnam (1993) e Costa (2003) são fatores como confiança e normas comuns que possibilitam as ações coordenadas, promovendo a cooperação social e melhorando o desempenho das instituições. O desempenho destas instituições é condicionado pelo amadurecimento de comportamentos cidadãos, que são vinculados às estruturas sociais (PUTNAM, 1993).

A matriz de "créditos e obrigações" proposta Coleman (1990) representa algumas promissórias (credit slips) que possuem validade, permitindo a relação de confiança. $\mathrm{O}$ apoio individual à coletividade credencia o membro a certos créditos próprios do grupo (BORDIEU, 1985). Segundo Lin (1999), a reputação é um sinal de ganhos sociais, podendo ser calculada de acordo com opiniões positivas e negativas que fazem sobre o indivíduo na rede. Diferentemente das trocas econômicas que são simétricas e recíprocas, as trocas sociais não o são, dependendo do reconhecimento do outro quanto ao débito ou crédito.

O capital social está conectado a uma estrutura social, assim devem existem três pressupostos para que se faça uso dele: existirem recursos dentro da estrutura social, estes recursos estarem acessíveis, e os agentes promoverem ações para o aproveitamento destes recursos. Desta forma, dois resultados principais podem ser esperados, sendo o primeiro de caráter instrumental para obtenção de novos recursos, e o segundo de caráter expressivo para manutenção dos recursos já obtidos (LIN, 1999). 
Existe uma demarcação que limita a rede de relações (família-comunidade), que é necessária para que exista densidade dentro da rede (LIN, 1999). Para Coleman (1990), os princípios de confiança, sanções e autoridade apenas são possíveis graças à essa limitação; em que recursos são mobilizados e circulam livremente em seu interior (PORTES, 1998). Para Bordieu (1985) a concentração de capital social é a base para a existência de todas as comunidades, seja a família ou a nação.

Esses recursos proporcionam três tipos de resultados, de acordo com as dimensões que o influenciam: a) Cooperação Técnico-Produtiva: os impactos diretos técnico-produtivos que diminuem os custos de produção e de transação, proporcionando maior eficiência (BRITTO, 2002; MACIEL; ALBAGLI, 2002; VILPOUX; OLIVEIRA, 2010); b) Cooperação Interorganizacional: os impactos indiretos, que permitem o melhor enfrentamento de problemas frente às instabilidades do mercado (BRITTO, 2002; MACIEL; ALBAGLI, 2002; VILPOUX; OLIVEIRA, 2010); c) Cooperação Tecnológica: os impactos dinâmicos, que permitem a livre circulação de informações na rede, proporcionando o aprendizado coletivo e a consequente melhoria da capacidade inovativa (BRITTO, 2002; FACCIN; GENARI; MACKE, 2010).

Existem pontos negativos permeando o conceito de capital social. Marteleto e Silva (2004) apresentam problemas como a formação de grupos corruptos e autoritários. Portes (1998, p. 15) identificou a "exclusão de estranhos, excessivas reivindicações dos membros do grupo, restrições às liberdades individuais e normas de nivelamento decadentes".

Existem formas de moldar as políticas públicas para que contribuam para a formação de capital social (EVANS, 1996; COSTA, 2003). Alternativas simples como dedução de impostos para quem contribui com a caridade, faculdades comunitárias, até mesmo obrigatoriedade da construção de varandas nas casas, permitem a maior interação da vizinhança (PUTNAM, 1995). Por outro lado, Brandão (2007) acredita que o Estado não deveria intervir, atuando somente sobre as falhas de mercado e facilitar o engajamento com o setor privado.

Putnam (1995) e Portes (1998) afirmam que a forma mais essencial de capital social é a família. Putnam (1995) apresenta alguns fatores que afetam à capitalização social: a) A imobilidade transacional dos habitantes constitui meio capaz de melhorar o engajamento cívico. Pessoas que tem certos vínculos ligados a estabilidade habitacional (casa própria), parecem criar raízes mais fortes e duradouras com a localidade; b) Características demográficas de todo tipo: menos casamentos, mais divórcios, menos filhos, rendas mais baixas etc. Além de mudanças econômicas, demonstradas pela substituição de mercearias por supermercados, e a seguir, dos supermercados pelas compras online; c) A revolução tecnológica no lazer apresenta uma série de características que individualizam o uso de nosso tempo livre, afetando as trocas interpessoais que aconteceriam nesse período, sendo o exemplo maior a televisão. A tecnologia permite que as pessoas satisfaçam completamente suas preferências, mas afeta consideravelmente o capital social que seria formado se fossem utilizadas formas mais antigas de entretenimento. Assim, surgiram novas tecnologias (teatros por cinemas, por exemplo) que gradualmente substituíram as anteriores, criando um cordão de isolamento alicerçado em uma nova realidade virtual (PUTNAM, 1995).

Lin (1999) discorda de Putnam (1995), ao afirmar que as redes cibernéticas propiciam uma revolução, possibilitando às redes empreendedoras acesso a recursos não antes 
disponibilizados. Desta forma, existe um número crescente de participantes regidos por novas regras, que vem sendo instituídas conforme o consenso de seus usuários, sem colonialismos ou formas de contenção imperialista.

O capital social é um conceito em construção, que necessita de maiores estudos empíricos que colaborem com sua teorização e demonstrem sua aplicabilidade e funcionalidade. Considerado ainda um conceito em "fraldas", pois depende de vários detalhes em escala microeconômica para que seja validado (HIGGINS, 2005). Portes (1998) e Marteleto e Silva (2004) explicitam que o conceito não deve ser entendido como uma panaceia, com o poder de solucionar todos os males e derrubar as barreiras ao desenvolvimento. Albagli e Maciel (2002) estabelecem que seu poder é limitado e dependente de outros recursos para que possa ser catalisado.

\section{Metodologia}

Este artigo comparou as percepções sobre o capital social de Brasília em nativos e não-nativos. Foram consideradas nativas aquelas pessoas nascidas e criadas em Brasília. Desta forma, esse estudo caracteriza-se como qualitativo, descritivo e indutivo. A estratégia de investigação foi o estudo "multicasos", que segundo a definição de Yin (2010), permite a comparação entre dois casos (ou como nesta situação, entre dois grupos de participantes).

Os participantes da pesquisa foram oito estudantes de Pós-Graduação de uma Universidade pública de Brasília, sendo metade deles natural à cidade. A escolha por estudantes de PósGraduação decorreu da crença de que muitos estudantes fossem não-nativos, fato que facilitaria a coleta de dados sobre as percepções desse grupo. No entanto observou-se justamente o contrário.

Primeiramente, para estabelecer comparações sobre entre esses grupos foi necessário mensurar o capital social existente. Adkins (2008) e Nieminen et al. (2008) afirmam que não existe consenso quanto a isso. Segundo a Organização para a Cooperação e Desenvolvimento Econômico (OECD, 2000), a mensuração do capital social é um assunto emergente. Faccin, Genari e Macke (2010) estabelecem que os valores sociais fogem ao racionalismo econômico, e desta forma, os indicadores deveriam ser subjetivos e intangíveis.

Para Albagli e Maciel (2002) capital social não pode ser medido ou quantificado, e apenas os aspectos qualitativos podem ser analisados, devido ao caráter inconstante da dinâmica social. Putnam (1993) por sua vez, acredita que de acordo com o nível de associativismo é possível medir o capital social embutido. Costa (2003) por outro lado, não acredita que a quantidade de associações seja relevante, mas a qualidade das participações que determinam a comunidade cívica. Bordieu (1985) engloba ambas as perspectivas, considerando a quantidade e qualidade de redes estáveis e duradores na comunidade para mensurar o capital social. Outra forma de mensuração parte da observação de relações mais seguras e institucionalizadas na localidade, possibilitando o estabelecimento de compromissos formais entre os agentes (MULS, 2008).

Desta forma, é explícito que não há consenso sobre a melhor forma de mensurar o capital social. Para Putnam (1995), engajamento cívico e confiança poderiam apresentar indícios do capital social existente. Neste sentido, visando delimitar o estudo, a pesquisa concentrou-se profundamente nas questões de confiança, de maneira que se pudesse ter condições de inferir 
sobre os diferentes níveis de capital social. Callahan (1996) afirma que embora seja difícil medir o capital social, podemos inferir sobre seus poderosos efeitos.

Capital social é um assunto essencialmente subjetivo; contudo a pesquisa de artigos, teses e dissertações demonstrou que o assunto é estudado sempre quantitativamente. Estes estudos identificam os grupos com os quais os indivíduos se relacionam, e aplicam questionários contendo escalas likert para cada um desses relacionamentos, na tentativa de medi-lo.

A forma mais comum para mensuração do capital social é o método "gerador de posições" criado por Lin, no entanto, esse método não identifica os recursos presentes na rede (NIEMINEN ET AL., 2008; MATOUS; OZAWA, 2010). Vários outros estudos como o de Guillen, Coromina e Saris (2011), tentam estabelecer o nível de capital social por meio da criação de escalas, porém afirmam que a criação de categorias não é precisa.

A pesquisa qualitativa justifica-se não apenas pela subjetividade do tema, no qual é necessário esclarecer os elementos ontológicos pela perspectiva dos entrevistados, mas também para validar as afirmações à partir de situações concretas. Tuan e Harpham (2005) perceberam a importância da utilização de métodos qualitativos em adição aos quantitativos, pois existem diferenças entre aquilo que os pesquisadores acham que perguntam e aquilo que os entrevistados acham que respondem. Narayan e Cassidy (2001) afirmam que teorias como a de capital social estruturam constructos que são essencialmente abstratos, e necessitam assim, de interpretações subjetivas para tradução de suas medidas. Flick (2009 p. 45) afirma que "dados de questionário dificilmente revelam o contexto de cada resposta; e isso apenas poderá ser alcançado a partir do uso explícito de métodos adicionais, tais como entrevistas complementares".

Este artigo apresenta uma proposta metodológica para tratar o tema qualitativamente, de acordo com a lacuna diagnosticada. Os respondentes participaram de entrevistas apoiadas por um roteiro contendo apenas questões abertas. Este roteiro sobre confiança foi estabelecido de maneira que permitisse entender o que os participantes identificam como sendo confiança, e se este conceito modifica a medida que os diferentes grupos com quem se relacionam são apresentados. Identificou-se nos relacionamentos se o nível de confiança é igual para todos os atores de um mesmo grupo; caso não, quais as características que o diferenciavam entre si. Por fim, os participantes atribuíram uma nota de um a cinco para o nível de confiança depositado aos diferentes indivíduos dentro do grupo.

Era esperado que a frequência das respostas e dos números que a representavam atingisse a saturação teórica, permitindo entender o significado nominal dos diferentes níveis das escalas, e assim estabelecer comparações entre os diferentes grupos de forma contundente. No entanto, não foi possível concluir esse objetivo metodológico da pesquisa, pois embora os participantes tenham apresentado certa frequência comum entre as respostas, os números variaram. Este resultado mantém em aberto essa lacuna metodológica e reforça as dificuldades em se utilizar escalas para tratar do tema.

Os dados foram coletados durante os meses de novembro e dezembro de 2011. Os respondentes se candidataram voluntariamente a participar da pesquisa, não recebendo qualquer tipo de remuneração para tal. Estes aceitaram os termos da entrevista, bem como sua gravação. As entrevistas foram transcritas e analisadas por meio da análise de conteúdo. Flick 
(2009) afirma que a característica essencial da análise de conteúdo é a elaboração de categorias de análise. A elaboração das categorias de análise foi por grade aberta, que segundo Vergara (2005) permite que as categorias sejam criadas no decorrer da pesquisa. Bardin (2009) afirma que durante o processo de codificação para o estabelecimento de categorias é necessário algum tipo de recorte. Desta forma, a justificativa para a elaboração destas categorias neste trabalho diz respeito às diferentes atribuições ontológicas apresentadas pelos entrevistados sobre o conceito de confiança. A Figura 1 apresenta os constructos que nortearam a pesquisa.

Figura 1 - Constructos da pesquisa

Confiança - $\mathrm{O}$ que entende por confiança? Como reconhece uma pessoa confiável? Considera importante ser reconhecida como uma pessoa confiável, isto é, manter uma reputação?

Confiança interpessoal - Confiança na família, em amigos, e amigos de amigos. O nível de confiança é igual para os membros de cada um desses grupos? Caso não, qual característica separa a pessoa mais confiável daquela menos confiável?

Confiança geral - Confiança em vizinhos, em emigrantes, em imigrantes? O nível de confiança é igual para os membros de cada um desses grupos? Caso não, qual característica separa a pessoa mais confiável daquela menos confiável?

Confiança nas organizações - Confiança no patrão, em professores, e em membros de organizações das quais faz parte. O nível de confiança é igual para os membros de cada um desses grupos? Caso não, qual característica separa a pessoa mais confiável daquela menos confiável?

Confiança em autoridades públicas - Confiança em policiais, em juízes e na imprensa. O nível de confiança é igual para os membros de cada um desses grupos? Caso não, qual característica separa a pessoa mais confiável daquela menos confiável?

Confiança nas instituições públicas - Confiança no governo do Distrito Federal, em membros do legislativo e na presidenta da república. O nível de confiança é igual para os membros de cada um desses grupos? Caso não, qual característica separa a pessoa mais confiável daquela menos confiável?

Fonte: Elaborado pelo autores, 2018.

\section{Resultados}

\subsection{Caracterização dos Grupos de Participantes}

O grupo de nativos foi formando por três mulheres e um homem, a idade dos participantes variou entre 24 e 35 anos, e sua renda entre 12000 e 20000 reais. Apenas um dos participantes dedica-se exclusivamente à vida estudantil, sendo que o restante alia seu emprego às atividades de Pós-Graduação. Apenas um dos participantes tem religião, sendo este católico. Todos os quatro pretendem continuar morando em Brasília, por gostar da forma como a cidade é estruturada, por já ter uma vida formada na cidade, ou devido as boas oportunidades de trabalho e convivência que lhes proporciona.

O grupo de emigrantes foi formado por três homens e uma mulher, a idade dos participantes variou entre 22 e 40 anos, e sua renda entre 2000 e 9000 reais. Todos os quatro se dedicam exclusivamente a vida estudantil, na qual três deles são estudantes de mestrado e um de doutorado. Com relação a religião, metade são católicos e metade são espíritas. Apenas um dos participantes afirmou não ter a intenção de continuar morando em Brasília. Metade dos indivíduos justificou a permanência em Brasília por motivos profissionais, como um local que detém melhores oportunidades.

Os resultados demonstram que a maioria dos participantes de ambos os grupos não querem se mudar de Brasília, principalmente devido as oportunidades profissionais que a cidade 
proporciona. Para Putnam (1995) a imobilidade transacional dos indivíduos pode ser um indício da presença de capital social. Callahan (1996) elenca alguns fatores que auxiliam no crescimento de capital social, como: estabelecer vínculos pessoais, mudar-se raramente, ser membro de comunidades religiosas, entre outros.

Com relação a religião, os não-nativos apresentaram participação em organizações religiosas bastante superior aos nativos. Coleman (1990) estabelece que o enquadramento em organizações coletivas é uma forma de ter acesso aos recursos existentes, em que o indivíduo participa de forma a facilitar suas ações.

No que se refere a renda familiar, esta foi sensivelmente superior em nativos. Callahan (1996) afirma que quanto maior a renda, menor é a quantidade de capital social existente, pois o aumento da renda diminui a dependência com relação a outros indivíduos. Matous e Ozawa (2010) afirmam que em contextos de baixa renda como favelas, o capital social é crucial para a sobrevivência dos moradores.

\subsection{Confiança}

Entre os nativos, apenas um dos participantes afirmou que confiança é a "esperança que se tem no outro" (Entrevistada 1), o restante afirmou estar relacionado com a coerência da pessoa. Dentre os fatores que afetam a confiança foram citadas experiências anteriores e o tempo de convivência. Os participantes em geral disseram reconhecer uma pessoa confiável quando seu discurso e suas atitudes são coerentes. Todos consideraram importante serem reconhecidos como pessoas confiáveis. $O$ relato da entrevistada 2 descreve bem a percepção do grupo quanto ao reconhecimento da reputação: "no trabalho, nossas ações terão maior credibilidade e mais oportunidades poderão surgir em consequência disso. Já com as pessoas da família e com amigos, é importante para criarmos relações mais próximas, transparentes e verdadeiras" (Entrevistada 2). Segundo Higgins (2005) o capital social tem duas abordagens, uma em que as assimetrias de informação facilita na obtenção de recursos, e outra em que as simetrias estruturam as relações sociais.

Os emigrantes tiveram dificuldade em conceituar confiança. As respostas foram construídas em torno de ter segurança em algo, da relação entre a expectativa e a realidade. No que se refere ao reconhecimento de uma pessoa confiável, os entrevistados afirmaram que a confiança não é algo simplesmente adquirido, mas algo que deve ser construído. Neste contexto, a afinidade da relação que se tem com a pessoa, e o tempo de relacionamento surgiram como variáveis importantes para sustentar a relação de confiança. Os participantes sem exceção afirmaram que manter uma reputação é algo importante, Lin (1999) estabelece que a reputação é um sinal de ganhos sociais dentro da estrutura, construídas a partir de opiniões positivas e negativas do indivíduo. Para Bordieu (1985), a reputação apenas gera retornos a pessoa quando existe o reconhecimento quanto do débito.

Pode-se afirmar que em ambos os grupos a confiança foi conceituada de forma semelhante, e consideram importante serem reconhecidos como pessoas confiáveis (reputação). Ambos os grupos consideraram a variável "tempo de relacionamento" como importante para estabelecer a relação de confiança. $O$ grupo de nativos considerou importante a variável "experiências anteriores", e o grupo de emigrantes a variável "afinidade". 


\subsubsection{Confiança interpessoal}

No que se refere a confiança na família, três dos quatro entrevistados do grupo de nativos afirmaram confiar em sua família; um único indivíduo disse confiar em apenas algumas pessoas. Esta última pessoa disse não confiar, para manter uma margem segura para eventuais surpresas. Os que confiam afirmaram que "convivência" e "similaridade de princípios" são variáveis importantes na relação de confiança. Com relação a confiança depositada em amigos, metade dos entrevistados afirmaram confiar em todos os amigos, enquanto a outra metade afirmou confiar apenas em alguns. Os participantes que apresentaram respostas positivas, afirmaram que "tempo" e "convivência" são variáveis importantes na relação. Os participantes que apresentaram restrições quanto a alguns amigos, afirmaram que a variável "bens materiais" (como dinheiro ou carro) interferem na relação de confiança. Com relação a confiança depositada em amigos de amigos, todos os participantes afirmaram não confiar. $O$ depoimento da entrevistada 2 sintetiza bem as percepções do grupo: "Ser amigo de um amigo não garante credibilidade ou qualquer outra concepção que eu não tenha constatado por mim mesma".

Os emigrantes afirmaram confiar em suas famílias. Os entrevistados afirmaram que a confiança em suas famílias é irrestrita, pois são as pessoas que te apoiam sempre, independentemente da situação. No entanto, afirmaram que o nível de confiança não é igual entre os familiares, no qual aqueles "mais próximos" (pai, mãe, irmãos e filhos) são mais confiáveis do que aqueles parentes mais distantes.

No que se refere à confiança depositada em amigos, todos os entrevistados afirmaram confiar em seus amigos. Porém, não confiam em todos os amigos da mesma forma, variáveis levantadas como importantes foram "convivência", "afinidade" e "histórico". A resposta do participante 4 resume bem o conceito das opiniões do grupo: "Depende de quem são esses amigos, eu acho que eu confio pelo histórico, pelo convívio, pelo quanto você conhece essa pessoa. Eu confio porque já existiram várias situações em que eu pude confiar neles". Em relação a confiança depositada em amigos de amigos, três dos quatro respondentes afirmaram não confiar, isto é, a confiança depositada um indivíduo não é "aval" para que se confie em outro. O único participante que afirmou confiar, se justificou de maneira genérica, dizendo que todas as pessoas merecem nossa confiança.

Com relação a confiança depositada na família, pode-se afirmar que os grupos foram relativamente homogêneos, pois apenas um indivíduo de nativos afirmou não confiar em todos os membros da família. Pode-se afirmar que de maneiras diferentes as variáveis importantes a relação de confiança foram semelhantes ("parentes mais próximos" e "similaridade de princípios" e "conveniência"). Enquanto apenas metade dos participantes do grupo nativos afirmou confiar em seus amigos, todos os integrantes do grupo emigrantes afirmaram confiar. Variáveis importantes nesta relação foram "convivência" e "histórico". No que se refere a confiança em amigos de amigos, sete dos oito participantes da pesquisa afirmaram que a confiança em uma pessoa não faz com que se possa confiar em outra.

\subsubsection{Confiança geral}


No grupo dos nativos, todos os quatro participantes afirmaram não confiar nos vizinhos, justificando que não os conhecem. A resposta da entrevistada 1 foi bastante interessante: "Não confio neles porque não os conheço, embora more no prédio há 16 anos". Com relação a confiança em emigrantes e imigrantes, todas as pessoas afirmaram ser indiferentes quanto a esse fato.

Os participantes do grupo de emigrantes afirmaram não confiar em seus vizinhos, pois não mantém qualquer tipo de relacionamento com estes. $O$ entrevistado 4 foi bem contundente ao afirmar que: "Nem conheço meus vizinhos. Juro, eu não sei a cara... Eu não sei o rosto deles!" (Entrevistado 4). Com relação a emigrantes e imigrantes, os participantes afirmaram não ter qualquer tipo de restrição com o fato destes terem vindo de fora.

Todos os participantes afirmaram não confiar em seus vizinhos, pois não mantém qualquer tipo de relacionamento com estes. Tratando-se tanto dos emigrantes, quanto dos imigrantes, todos os participantes mostraram-se indiferentes com relação a essa característica. Portes (1998) estabelece que a exclusão de estranhos é um indicador negativo do capital social da localidade.

\subsubsection{Confiança nas organizações}

Os participantes do grupo nativos tiveram respostas totalmente diferentes entre si no que se refere a confiança no "patrão". Um participante afirmou dedicar-se exclusivamente aos estudos; um disse não confiar no patrão, pois o considera mentiroso, político e estrategista ao extremo; um afirmou confiar nele, pois a empresa Ihe oferece uma boa estrutura. Um dos participantes afirmou não ter opinião formada sobre o assunto. Assim, não houve consenso entre o grupo de participantes sobre esse item.

No que se refere a confiança em professores, todos afirmaram confiar em professores. As variáveis importantes a essa relação citadas foram "conhecimento" e "segurança no conteúdo transmitido". No que se refere a confiança em "membros de organizações das quais faz parte" as opiniões foram divididas, pois metade afirmou não confiar e a outra metade afirmou confiar apenas em relação a característica comum que os une à organização.

Os participantes do grupo emigrantes afirmaram não estar trabalhando no momento, pois estão se dedicando exclusivamente aos estudos. Todos os indivíduos afirmaram confiar em seus professores, neste sentido a confiança está ligada à segurança que a pessoa sente na figura do professor. As variáveis levantadas como importantes para criar a situação de confiança foram "conhecimento teórico", "segurança nos conteúdos estudados" e "convivência". No quesito confiança em membros de organizações das quais faz parte, as opiniões foram divididas, metade não confia nos membros, enquanto que a outra metade confia pelo fato de entender que estas pessoas compartilham alguns valores que os tornam mais parecidos entre si.

A característica fundamental entre os grupos no item "confiança no patrão", foi que todos os integrantes do grupo de emigrantes não mantém vínculo empregatício, fato que inviabiliza a comparação entre os grupos. Todos os integrantes de ambos os grupos afirmaram confiar em seus professores, onde variáveis consideradas importantes foram: "conhecimento", "segurança no conteúdo" (ambos os grupos), e "convivência" (apenas emigrantes). Ambos os grupos ficaram divididos em relação à membros de organizações das quais faz parte. Metade afirmou não confiar nestes indivíduos, enquanto metade afirmou confiar por entender que existem 
características que são parecidas entre si. A participação em associações voluntárias auxilia na criação de capital social (CALLAHAN, 1996), que só existe quando é compartilhado (NARAYAN; CASSIDY, 2001).

\subsubsection{Confiança em autoridades públicas}

No que se refere a confiança depositada em policiais por participantes nativos, todos os quatro foram enfáticos em afirmar que não confiam em policiais. Variáveis importantes que afetam essa relação de confiança foram "corrupção" e "abuso de poder". O relato do entrevistado 4 demonstra uma situação em que ocorreu abuso de poder.

A polícia no Brasil e principalmente em Brasília é muito perigosa. Costumo sair muito a noite e eles na balada são um perigo. Dão carteirada, entram armados, ficam bêbados e arrumam confusão. Um amigo teve seu carro alvejado por um policial bêbado que brigou com ele. Resumindo tenho medo da polícia (Entrevistado 4).

Com relação à confiança depositada em juízes uma entrevistada afirmou confiar devido à autoridade pública da função e dois afirmaram ser indiferentes ao fato de ser juiz, enquanto um afirmou não confiar no discernimento que estes fazem das leis. Este último indivíduo disse que o único fato que os separa da população em geral é o fato de terem decorado leis para passar em concurso público. Com relação a confiança na imprensa, todos os participantes disseram não confiar. Entre as variáveis que afetam a confiança foram identificadas a "manipulação" e a "tendenciosidade".

Os participantes emigrantes, três responderam confiar na polícia, mas não em policiais. Metade dos entrevistados frisaram que respeitam o papel público da polícia, e seu respectivo papel e autoridade perante a sociedade. No entanto, fatores como "corrupção" e "inclinações negativas de caráter" fazem com que os indivíduos confiem menos na polícia. Apenas um dos entrevistados afirmou não confiar de qualquer forma na polícia, devido à experiências anteriores ocorridas.

Com relação à confiança depositada em juízes, todos os entrevistados afirmaram confiar. Justificaram essa confiança baseada na "autoridade pública" do juiz e a expectativa de sua "função para a defesa da sociedade". Metade dos entrevistados afirmou que devido a seu "grau de instrução", merecem um maior respeito. Com relação a confiança na imprensa, as opiniões foram divididas. Metade dos entrevistados confia porque consideram a "única forma de ter acesso a notícias", enquanto metade não confia porque a considera "tendenciosa", como descreve um dos entrevistados: "o foco que a imprensa dá sobre as notícias é tendencioso, de acordo com interesses de patrocinadores" (Entrevistado 2).

Enquanto todos os indivíduos do grupo nativos afirmaram não confiar em policiais, a maior parte dos emigrantes afirmou confiar. Variáveis importantes nessa relação foram: "corrupção" (ambos os grupos), "abuso de poder" (apenas nativos), e "inclinações negativas de caráter" (apenas emigrantes). O comportamento das respostas do item "confiança em juízes" foi difuso entre os nativos. Os emigrantes demonstraram em sua totalidade confiar em juízes, em que "autoridade pública", "função para a defesa da sociedade", e "grau de instrução" foram consideradas variáveis importantes. Capital social produz ordem pública, assim como traz 
segurança para aqueles que o detêm. Isso é importante quando se é novo, velho, doente, dependente ou está em problemas (CALLAHAN, 1996).

Nenhum dos participantes do grupo nativos afirmou confiar na imprensa, e apenas metade do grupo imigrantes afirmou confiar. Variáveis relevantes a essa falta de confiança foram: "tendenciosidade" (ambos os grupos) e "manipulação" (apenas nativos).

\subsubsection{Confiança nas instituições públicas}

Os participantes nativos foram unânimes em afirmar que não confiam no governo do Distrito Federal. Dentre as variáveis que afetam essa relação foram citadas a "corrupção" e a "ineficiência".

Salvo raras exceções, não confio na política e nos políticos do Brasil. O individualismo, o paternalismo e o egoísmo são hoje marcas culturais no Brasil e isto está extremamente atrelado à política do país. Além disso, a cada governo, os escândalos e as corrupções recorrentes ratificam o descrédito das instituições governamentais e a sensação de insegurança (Entrevistada 2).

O comentário se manteve ao tratar sobre os membros do legislativo, sendo incluído o fator "manutenção do poder político" como afetando esse relacionamento. No que se refere a confiança depositada ao presidente em exercício na ocasião da coleta de dados, às opiniões foram divididas. Metade afirmou não confiar na presidente devido ao "partido político" do qual faz parte e de suas "políticas populistas". A outra metade afirmou confirmar na "competência individual", no entanto acreditam que apenas isso não é capaz de fazer as coisas acontecerem. No grupo de participantes emigrantes as opiniões foram divididas sobre a confiança depositada no governo do Distrito Federal e membros do legislativo. Metade dos participantes afirmou confiar nestes, pois ainda que existam problemas, eles representam a legitimidade democrática inerente ao sistema político-eleitoral do país. Com relação a confiança depositada na presidente da república, todos os participantes afirmam confiar. Os participantes entendem a figura presidencial como sendo diferenciada, pois embora existam escândalos com relação a corrupção, a figura presidencial está bastante vinculada ao seu papel carismático, conforme descrito pelo entrevistado 4: "É meio contraditório porque eu não confio no governo, mas eu confio na figura dela. Eu confio nela porque é a função dela ser confiável” (Entrevistado 4).

Todos os participantes do grupo nativos afirmaram não confiar no governo do Distrito Federal, e apenas metade do grupo emigrantes afirmou confiar (sendo esta confiança baseada em sua legítima representatividade democrática). $O$ padrão de respostas se repetiu para os membros do legislativo. Com relação à presidente da república, metade dos grupos nativos afirmou confiar, enquanto todos os integrantes do grupo emigrantes afirmar. Demonstrando que a figura presidencial é bastante diferenciada em relação a outras posições políticas. Uma maneira de medir o capital social é pelo nível de confiança nas instituições (GUILLEN; COROMINA; SARIS, 2010). Para finalizar, é necessário o estabelecimento de critérios para tratar sobre o conceito de capital social, pois está sendo utilizado com vagas interpretações e indiscriminada aplicação (OORSCHOT; ARTS; GELISSEN, 2006). 


\section{Conclusão}

O objetivo geral deste artigo foi comparar o capital social existente em Brasília na perspectiva de nativos e emigrantes. Para isso, utilizou-se a confiança como um indicador da presença de capital social entre os indivíduos. Embora o conceito capital social já exista há algum tempo, existe uma dificuldade bastante grande para teorias mais femininas transpassarem a barreira do viés masculino e obterem reconhecimento. Por meio desta breve revisão, pode-se observar as vantagens e problemas decorrentes da maior interação e integração dos indivíduos. Assim, o capital social surge como uma nova variável para explicar as causas do desenvolvimento.

A pesquisa debruçou-se sobre os relacionamentos envolvendo a confiança entre indivíduos, assim como sua confiança nas autoridades públicas e as instituições. Os principais resultados indicam que dentre os diferentes relacionamentos citados no decorrer do texto, os emigrantes sensivelmente confiam mais em seus pares, nas autoridades públicas e nas instituições do que os participantes nativos.

Esta pesquisa contribui para: (a) entender as percepções referentes a confiança entre nativos do Distrito Federal e emigrantes; assim como, este estudo permite (b) inferir sobre o capital social existente em cidades "construídas" artificialmente. Dentre as limitações do estudo pode ser citado o fato da pesquisa ter se apoiado sobre o grupo de alunos de pós-graduação para que o acesso a emigrantes fosse facilitado, no entanto ocorreu justamente o contrário, houve grande dificuldade de encontrar entre esses estudantes, membros completamente nativos à cidade. Dentre as sugestões para trabalhos futuros identifica-se englobar não só questões referentes a confiança, mas também referentes a engajamento cívico.

\section{Referências Bibliográficas}

ALBAGLI, S.; MACIEL, M. L. Capital social e empreendedorismo social. (Org.) LASTRES, M. H. et al. Proposição de políticas para a promoção de sistemas produtivos locais de micro, pequenas e médias empresas. UFRJ, 2002.

BORDIEU, P. The forms of capital. In: Handbook of theory and research for the sociology education. Ed. JG Richardson. New York: Greenwood, 1985.

BRANDÃO, C. Território e desenvolvimento: as múltiplas escalas entre o local e o global. Campinas: Editora UNICAMP, 2007.

BRITTO, J. Cooperação interindustrial e redes de empresas. In: KUPFER, D.; HASENCLEVER, L. (Org.). Economia industrial: fundamentos teóricos e práticos no Brasil. Rio de Janeiro: Campus, 2002.

BURREL, G.; MORGAN, G. Sociological Paradigms and Organizational Analysis. Aldershot: Ashgate Publishing Co, 1979.

Callahan, S. The capital that counts. Commonweal, 1996.

CASAROTTO FILHO, N.; PIRES, L. H. Redes de pequenas e médias empresas e desenvolvimento local: estratégias para a conquista da competitividade global com base na experiência italiana. 2 ed. São Paulo: Atlas, 2001.

COLEMAN, J. S. Foundations of social theory. Cambridge: Belknap press of Harvard university press, 1990. 
COSTA, M. A. N. Sinergia e capital social na construção de políticas sociais: a favela da mangueira no Rio de Janeiro. Revista de Sociologia Política, 21, 147-163, 2003.

EVANS, P. Government action, social capital and development: Reviewing the evidence on synergy. World Development, 24(6), 1119-1132, 1996.

FACCIN, K.; GENARI, D.; MACKE, J. Capital social: recurso facilitador da inovação em gestão. Revista de Administração e Inovação, 7(4), 206-233, 2010.

FLICK, U. Introdução à pesquisa qualitativa. 3 ed. Porto Alegre: Artmed, 2009.

FUKUYAMA, F. Confiança: as virtudes sociais e a criação da prosperidade. Rio de Janeiro: Rocco, 1996.

GUILLEN, L.; COROMINA, L.; SARIS, W. E. Measurement of social participation and its place in social capital theory. Social Indicators Research, 100, p. 331-350, 2011.

HIGGINS, S. S. Os fundamentos teóricos do capital social. Chapecó: Argos Editora Universitária, 2005.

LIN, N. Building a network theory of social capital. Connections, 22(1), 28-51, 1999.

MATOUS, P.; OZAWA, K. Measuring social capital in a Philippine slum. Field Methods, 22(2), p. 133-153, 2010.

MARTELETO, R. M.; SILVA, A. B. O. Redes e capital social: o enfoque da informação para o desenvolvimento local. Revista de Ciência da Informação, 33(3), 41-49, 2004.

MULS, L. M. Desenvolvimento local, espaço e território: o conceito de capital social e a importância de formação de redes entre organismos e instituições locais. Revista EconomiA, Brasília, v. 9, n. 1, p. 1-21, 2008.

NARAYAN, D.; CASSIDY, M. F. A dimensional approach to measuring social capital: development and validation of a social capital inventory, Current Sociology, 49(2), p. 59-102, 2001.

NIEMINEN, T. et al. Measurement and socio-demographic variation of social capital in a large population-based survey. Social Indicators Research, 85, p. 425-423, 2008.

OORSCHOT, W. V.; ARTS, W.; GELISSEN, J. Social capital in Europe: measurement and social and regional distribution of a multifaceted phenomenon. Acta Sociologica, 49(2), p. 149-167, 2006.

ORGANISATION FOR ECONOMIC CO-OPERATION AND DEVELOPMENT. Glossary of statistical terms. Disponível em http://stats.oecd.org/glossary/detail.asp?ID=3560. Acesso em outubro de 2001.

PORTES, A. Social capital: Its origins and applications in the modern sociology. Annu. Rev. Sociology, 24, 1-24, 1998.

PUTNAM, R. D. Making democracy work: civic traditions in modern Italy. Princeton: Princeton University Press, 1993.

PUTNAM, R. D. Bowling alone: America's declining social capital. Journal of Democracy, 65-78, 1995.

PUTNAM, R. D. Bowling alone: the collapse and revival of American Community. New York: Simon \& Schuster, 2000.

SCOTT, R. W. Organizations: Rational, natural, and open systems. 4 ed. New Jersey: Prentice Hall, 1998.

VILPOUX, O. F., \& Oliveira, E. J. Instituições informais e governanças em arranjos produtivos locais. Revista Economia Contemporânea, (14)1, 85-111, 2010. 